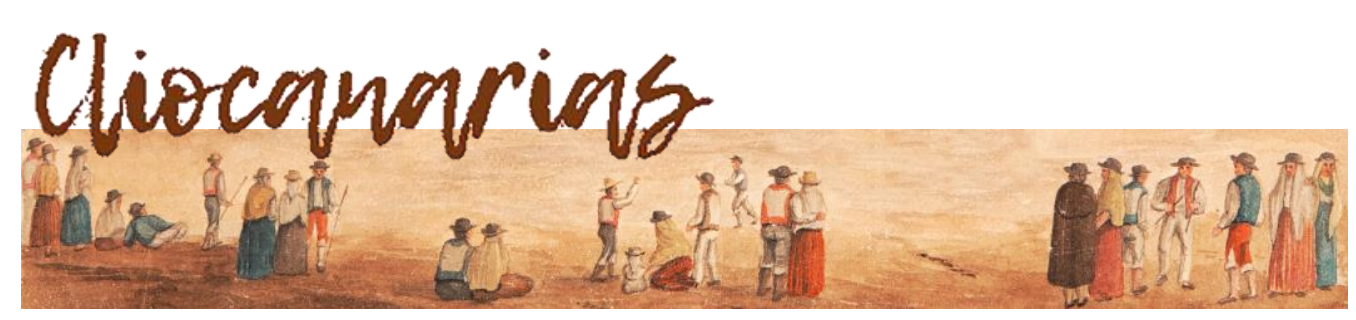

ISSN 2695-4494

https://doi.org/10.53335/cliocanarias.2021.3.17

\title{
CANARIOS EN EL COMERCIO Y EL CONTRABANDO EN EL RÍO DE LA PLATA. SIGLO XVII
}

\author{
CANARIES IN TRADE AND SMUGGLING IN THE RÍO DE LA PLATA. \\ $17^{\text {th }}$ CENTURY
}

Nora SIEGRIST*

RESUMEN: La historiografia recoge gran cantidad de obras sobre lo sucedido en el siglo XVII en el Río de la Plata con comentarios sobre el accionar de pobladores canarios. En medio del comercio y del contrabando que sobre el puerto de Buenos Aires se desarrolló, se formaron dos grupos de personas, unos llamados "beneméritos" y otros "confederados". En esta colaboración se destaca la participación que tuvieron en ellas dos tinerfeños: Bernabé González Filiano y Simón Valdez, y su inserción en la sociedad.

Palabras Clave: Canarios, Río de la Plata, siglo XVII, contrabando.

ABSTRACT: The historiography collects a great deal of works on what happened in the 17th century in the Río de la Plata with comments on the actions of Canarian settlers. In the middle of the trade and smuggling that developed over the port of Buenos Aires, two groups of people were formed, some were called "beneméritos" and the others named the "confederados". In this collaboration, the participation of two people from Tenerife stands out: Bernabé González Filiano and Simón Valdez, and their insertion into society.

KEY WORDS: Canaries, Río de la Plata, 17th century, smuggling.

\section{Introducción}

La historiografia contiene gran cantidad de obras sobre lo sucedido en el siglo XVII en el Río de la Plata y sus vinculaciones con pobladores canarios, con acontecimientos que hunden sus raíces en el último período del siglo anterior. En medio del comercio y del contrabando que se desarrolló, se formaron dos bloques o grupos de personas, unos llamados "beneméritos" y los otros

\footnotetext{
* Instituto de Investigaciones. Facultad de Ciencias Sociales (Pontificia Universidad Católica Argentina, Inv. (J.) CONICET). C. e.: nora.siegrist@gmail.com
} 
"confederados", dentro del orden político-social-económico de los que vivian en Buenos Aires ${ }^{1}$. Puede decirse que aquellos estaban formados por los que descendian de los primeros pobladores, la elite constituida por hombres y mujeres cuyos antepasados, en alguna ocasión de sus vidas, habían recibido encomiendas por parte de los monarcas en España.

La diferenciación de los "beneméritos" se acentuaba con respecto a los "confederados", integrados estos con un alto porcentaje de portugueses y extranjeros que buscaban activar el comercio exterior en general y el de la esclavatura, aprovechando las enormes ganancias que de ello resultaba. Esto los distinguía, asimismo, de los que vivian con mercancías derivadas de la tierra y sus frutos, animales, trigo, harinas, maderas... Se diferenciaban también en el hecho de que los "confederados" quisieron arraigarse como vecinos en la ciudad, situación que se lograba luego de una residencia de diez años, aparte de que buscaban contraer matrimonio con hijas de los "beneméritos". Es de destacar que la suma de ambas cosas aceleraba el proceso de prebendas ansiadas $^{2}$.

Con tales objetivos muchos lograron fijar sus posiciones en la escala social casando con las descendientes de los antiguos vecinos. Esto les otorgó un lustre honorífico e insospechado, les abrió las puertas a un nivel mayor, les otorgó la calidad de vecinos, más allá de que -en ocasiones- las dotes matrimoniales con que los progenitores las beneficiaron contaban con suertes de tierras, estancias, más chacras de miles de hectáreas en el territorio. Por consiguiente, agregó la posibilidad de beneficios de su explotación, consecuencia que - podría afirmarse - fue meta más que apreciada.

Aparte del trampolín hacia un estatus social y las riquezas derivadas de la unión con el género, se dijo que se obtenía la calidad de vecino, posición desde la que se podía optar a los puestos del Cabildo. Imposible resulta aquí hacer referencia a las especulaciones que esgrimieron ambos grupos desde que en su lucha interna se dirimían los cargos de dicha institución y los que resultaban de la administración pública.

El acercamiento a los gobernadores en turno fue otra secuencia que los "confederados" ansiaron como preciado valor. Se entiende que en estos juegos políticos se jugaron grandes intereses de contrabando en donde la mayoria de esos mandatarios también estaban involucrados. De hecho, el contrabando

\footnotetext{
${ }^{1}$ MOUTOKIAS, Zacarias: "Burocracia, contrabando y autotransformación de las élites: Buenos Aires en el siglo XVII". Anuario I. E. H. S., n. ${ }^{\circ}$ 3, Tandil, 1988; ídem: "Contrabando y sector externo en Hispanoamérica colonial", en CARMAGNANI, Marcelo, Alicia HERNÁNDEZ CHÁVEZ, Alicia y Romano RUGGIERO (coords.): Para una historia de América II, México, Fondo de Cultura Económica, 1999, pp. 172-197; PERUSSET VERAS, Macarena: «Elite y comercio en el temprano siglo XVII rioplatense", Fronteras de la Historia, n. ${ }^{\circ} 10$, ICANH, 2005; idem: "Conductas y procedimientos fuera de la ley: comercio ilícito, líderes y prácticas", en Universitas Humanística, n. ${ }^{\circ}$ 63, enero-junio de 2007, Bogotá, Colombia, 2007, pp. 203-239: [<http://www.scielo.org.co/pdf/unih/n63/n63a11.pdf.>]; ídem: Contrabando y sociedad en el Río de la Plata colonial, Buenos Aires, Editorial Dunken, 2006.

2 BIROCCO, Carlos: La élite de poder en Buenos Aires colonial: Cabildo y cabildantes entre los Habsburgos y los Borbones (1690-1726), tesis de posgrado, Universidad Nacional de La Plata, Argentina, Facultad de Humanidades y Ciencias de la Educación, 2015. Memoria Académica [<http://www.memoria.fahce.unlp.edu.ar/tesis/te.1167/te.1167.pdf>].
} 
respondia a una situación político-económica impuesta por la Corona. Al respecto, se expresó:

Fue el comercio ilegal, realizado a la sombra de aquellas disposiciones, lo que produjo mayor efecto. El contrabando llegó a ser en el Rio de la Plata una solución para sus necesidades, y a pesar de que no se le practicó en el siglo XVII con la intensidad que en otras partes de América, contribuyó a evitar el ahogo económico de la región. Los navios de registro autorizados por la Corona eran absolutamente insuficientes para mantener el tráfico. Muy de tarde en tarde, cada tres años o más, solian aportar a Buenos Aires un par de fragatas procedentes de España para cortar el aislamiento y remover un poco el estancamiento del comercio, como si el propósito hubiese sido solo evitar que la región tocase en la agonía y se produjese su despoblamiento... ${ }^{3}$.

En esta sociedad que participaba del contrabando, algunos otros hechos identificaban a los "confederados" desde que gustaban de las riquezas y de los objetos suntuarios. Por el contrario, los "beneméritos" habían transitado sus vidas con sacrificio en su lucha con la explotación de la tierra, mantenían el arraigo antiguo sin ostentaciones características de los primeros españoles y criollos, sus descendientes, en suelo rioplatense. No obstante, a lo largo del siglo XVII algunos de los "beneméritos" se fueron plegando a los que otrora eran sus enemigos.

\section{Bernabé González Filiano}

En estas circunstancias, tal vez uno de los más antiguos pobladores canarios que llegó a Buenos Aires fue Bernabé González Filiano ${ }^{4}$, nacido en Garachico, Tenerife, entre 1581-1590:

En la isla canaria de Tenerife, sobre escarpadas rocas circuidas de peñascos y acantilados que se hunden en el mar, acurrucada bajo la falda imponente del eruptivo Teide, se encuentra la villa de Garachico ${ }^{5}$.

Fue hijo legítimo de Diego González y Mencía Hernández de Oramas, de quienes obtuvo en herencia una importante casa de dos pisos que lindaba con las casas de don Diego de Cospedal y Grimaldo, junto asimismo a las del licenciado Montalvo, en su pueblo natal. El primero nombrado, pasado el tiempo y ya en su vejez, recordaría a sus hijos que las reclamaran como heredad de su pertenencia, desconociéndose cuál fue el fin de este asunto.

\footnotetext{
3 VILlALOBOS R., Sergio: Comercio y contrabando en el Río de la Plata y Chile, 1700-1811, Buenos Aires, Editorial Universitaria de Buenos Aires, 1965, p. 17.

${ }^{4}$ CIORANESCU, Alejandro: Diccionario Biográfico de canarios-americanos, Santa Cruz de Tenerife, 1992, 2 vols., p. 917. Cioranescu afirma que se llamaba Bernabé González Fullana (sic), al que en Argentina llamaban González Filiana. En realidad, en el Río de la Plata se lo conoció como González Filiano. Ese autor expresa que debió nacer por 1580. Agradezco los datos sobre la obra de Cioranescu que me fueron suministrados por el prof. José Miguel Rodríguez Yanes.

5 IBARGUREN, Carlos (h.): "González Filiano", Instituto Argentino de Ciencias Genealógicas, Revista del Instituto Argentino de Ciencias Genealógicas, n. ${ }^{\circ}$ 17, Buenos Aires, 1997, p. 113. FERNÁNDEZ DE BURZACO, Hugo: Aportes Biogenealógicos para un Padrón de Habitantes del Río de la Plata, Buenos Aires, 1988, vol. III, p. 264.
} 
Sobre González Filiano, un descendiente escribió en Buenos Aires en el siglo $\mathrm{XX}$ :

[...] Por su estirpe materna descendia de aborigenes canarios: los "guanches", altos, fornidos, alegres y valientes; de aquilinas narices, amplios labios y blancas dentaduras; cuya raza el arqueólogo francés Augusto Berthelot describe como "de tez curtida y rostro oval y descarnado, facciones regulares, frente saliente algo estrecha y grandes ojos vivos y rasgados, a veces verdosos, espesa cabellera rizada, que variaba del negro al rojo oscuro»6.

Figura 1

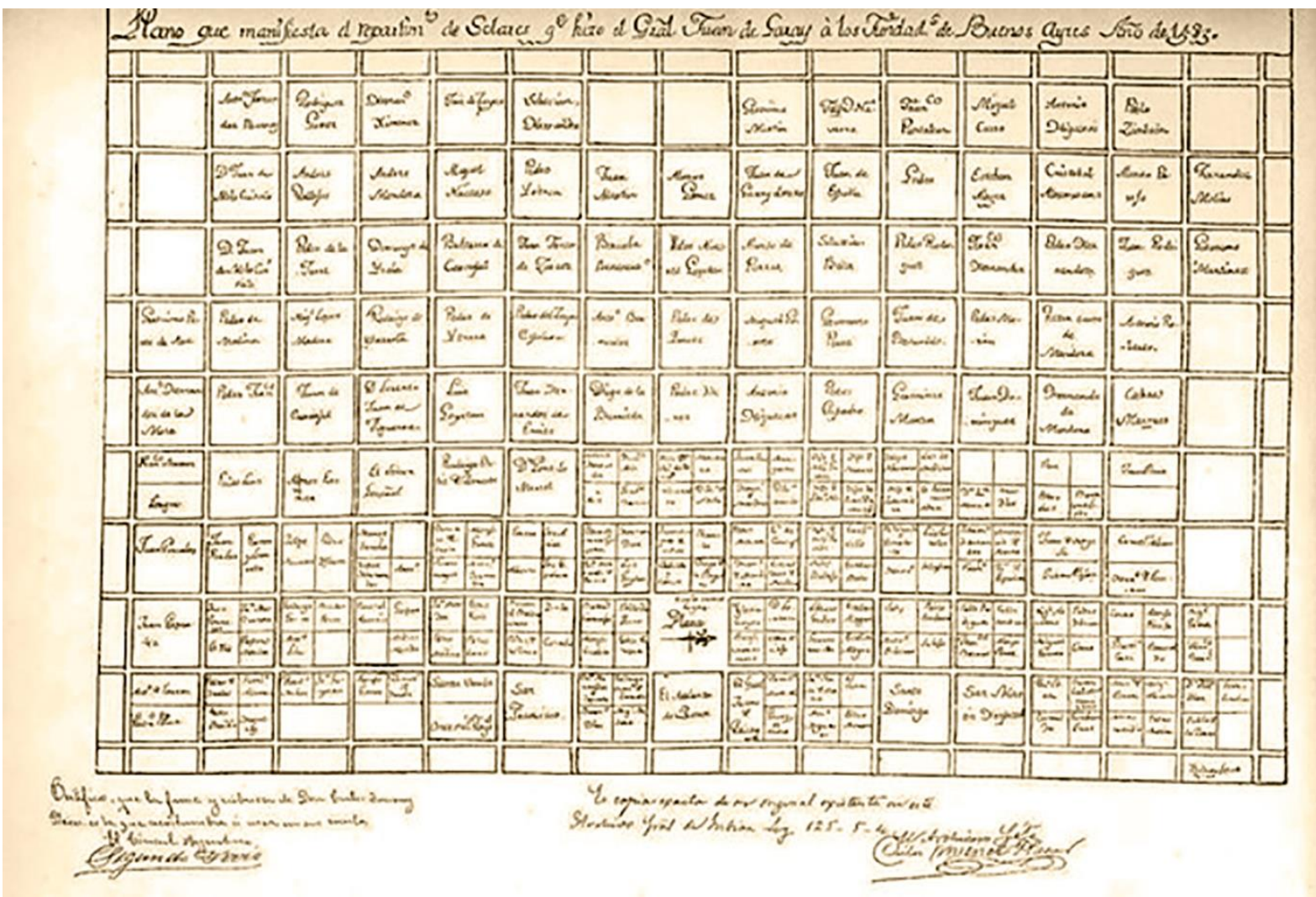

Plano que manifiesta el repartimiento de solares realizado por Juan de Garay primitivamente en lo que fue la ciudad de Buenos Aires (1583).

Aunque la diferencia de apellidos es notable, era hermano de Simón González de Castilla7. Don Bernabé González Filiano arribó a Buenos Aires en

6 IBARGUREN, C. (h.): "González Filiano"..., art. cit., p. 113.

7 MOLINA, Raúl A.: Diccionario Biográfico de Buenos Aires 1580-1720, Buenos Aires, Academia Nacional de la Historia, 2000, p. 321. José González Castilla, español, seguramente nacido en Canarias, sirvió a su majestad con 400 caballos para el refuerzo de la guardia de San Juan y el sitio de la colonia contra los portugueses en 1704. Fue teniente de gobernador de Santa Fe en 1706 lo que habla a las claras de la importancia de este núcleo de parentesco. En Santa Fe el día 2 de septiembre de 1700 el capitán José González de Castilla presenta título de teniente de gobernador de Santa Fe, otorgado por el gobernador Manuel de Prado Maldonado en Buenos Aires el 20 de julio de 1700, y certificación de haber abonado la media anata ante el tesorero de Santa Fe, Juan de los Ríos Gutiérrez. Presenta como fiadores a los capitanes Melchor de Gaete y Miguel Díez de Andino

[<https://actascabildo.santafe.gob.ar/actascabildo/default/buscar/1/01_01_1532-

31_12_1900/Gonzalez_de_Castilla_Jose_Teni-ente_de_Gobernador>].

https://doi.org/10.53335/cliocanarias.2021.3.17

4/Cliocanarias, ISSN 2695-4494, n. ${ }^{\circ} 3$ (2021), pp. 1-23, La Laguna (Canarias) 
1614 con vinculación directa en el comercio negrero. Llevaba consigo 30 "piezas" propias de esclavos. Con seguridad, tuvo en su vida varias situaciones para contar. Se sabe que en uno de sus viajes fue robado el navío que lo trasladaba por un barco pirata consiguiendo sobrevivir al episodio.

Figura 2

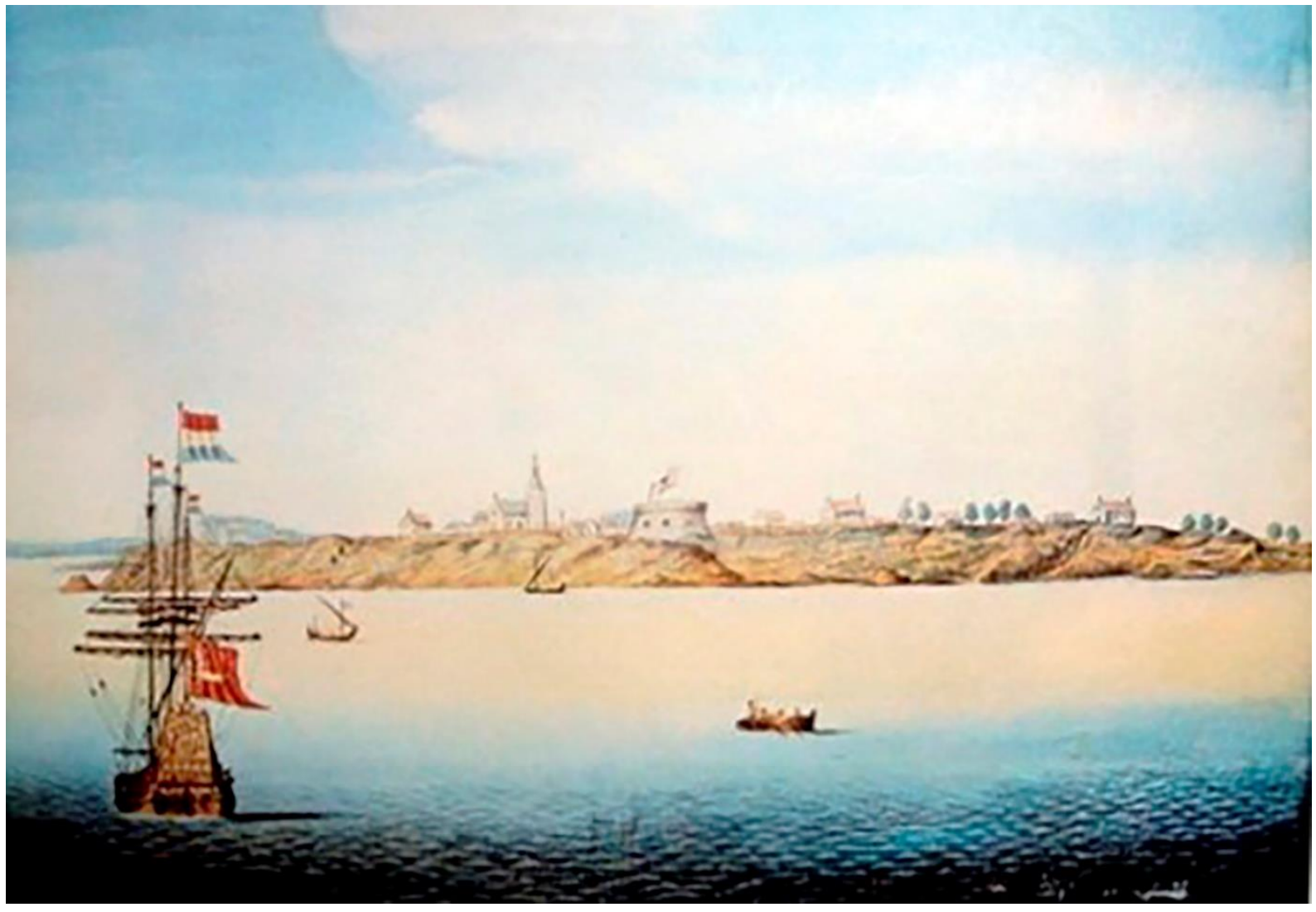

Puerto del Río de la Plata. Siglo XVII (Pintura de Aldo Verthoont) (Wikipedia.org).

Fue amigo y pariente político de Juan de Vergara $^{8}$, un prominente comerciante del grupo de los "confederados" en Buenos Aires que se oponían - como se dijo- a los "beneméritos". Poco después de su establecimiento, y como consecuencia de pertenecer a familia de renombre en Canarias (usó el indicativo de "don" antes del nombre desde su llegada), se le nombró procurador de Buenos Aires el 3 de enero de 1625.

En esa ciudad pronto contrajo matrimonio con mujer "castellana". La elegida fue doña Francisca Trigueros y Enciso (hija de Diego de Trigueros y Caro -exprocurador de Buenos Aires en 1608-y de Felipa Hernández de Enciso,

En el año 1705, de acuerdo con las mismas actas del Cabildo, logró licencia para sacar 6.000 cabezas de ganado vacuno; TRUJILLO, Óscar José: Consenso, negociación y conflicto en la Monarquía Hispánica: La élite de Buenos Aires en el XVII. Cfr.:

[https:/ / ri.unlu.edu.ar/xmlui/ bitstream/handle/rediunlu/244/Tesis\%20Trujillo.pdf?sequence $=18$ is Allowed $=y]$.

8 MOLINA, Raúl A.: "Juan de Vergara, señor de vida y haciendas en el Buenos Aires del siglo XVII", Boletín de la Academia Nacional de la Historia, n. ${ }^{\circ}$ XXIV, Buenos Aires, 1950, pp. 24-25. MOLINA, R. A.: Diccionario Biográfico..., op. cit., p. 775; idem: "El primer banquero de Buenos Aires. Jerarquía alcanzada por su descendencia", Revista de Historia Argentina y Americana, n. ${ }^{\circ}$ II, Buenos Aires, 1961. 
nieta del conquistador Martínez de Irala $)^{9}$, con quien se desposó en Buenos Aires el 13 de enero de 1622. El acto nupcial fue llevado a cabo por el comisario del Santo Oficio, el licenciado en cánones Francisco de Trejo. Sus padrinos fueron el ya indicado Juan de Vergara y la tercera cónyuge de este: doña María de Freyre. La novia era viuda de Tomás Rosende. Consta que llevó al matrimonio un caudal de 9.159 pesos. Doña Francisca testó el 7 de mayo de 1649 , ordenando su entierro en la iglesia de San Francisco ${ }^{10}$.

Crio a dos niños: Feliz y Francisco, a quienes dejó 200 pesos de herencia, designando albacea a su hijastro, el canónigo de la catedral Diego de Rosende Trigueros, nacido en 1619 en Buenos Aires ${ }^{11}$. Mejoró a sus hijas en el quinto de la herencia como ayuda de su futuro ${ }^{12}$.

Si se mencionan todos estos nombres se debe al complejo grupo de personas adineradas de la sociedad que González Filiano llegó a integrar, como luego puede observarse.

Figura 3

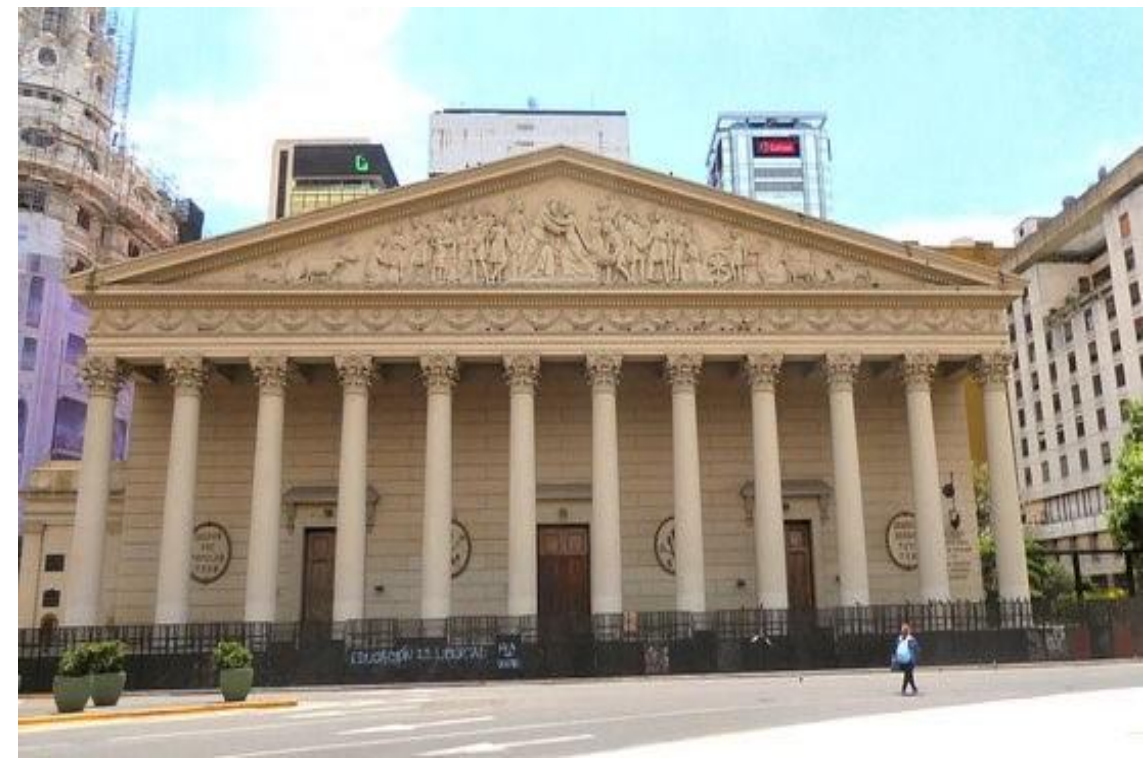

Imagen: Catedral de Buenos Aires, siglo XXI (foto de la autora)

En el transcurso de sus funciones políticas tuvo un grave altercado con el alguacil mayor Francisco González Pacheco al ser acusado como pasajero que entró en la ciudad sin licencia de su majestad y no poder tener ningún oficio,

\footnotetext{
9 IBARGUREN, C. (h.): "González Filiano", art. cit., p. 114. Una hermana de doña Francisca Trigueros y Enciso fue doña Isabel de Vega, quien contrajo matrimonio con Juan de Vergara. Doña Francisca era, por tanto, cuñada de Juan de Vergara.

10 Ibid., p. 115. Indica que los Trigueros tenían enterramiento en lugar especial. El autor afirmó que el 8 de abril de 1630, al día siguiente de morir doña Felipa Hernández de Enciso, su yerno González Filiano pidió que se depositaran los restos de aquella en la sepultura familiar, en el templo de San Francisco, donde los Trigueros tenían fundada una capellanía en las constituciones de la Cofradía de N. S. de la Limpia Concepción.

${ }_{11}$ MOLINA, R. A.: Diccionario Biográfico..., op. cit., p. 667, quien dice: Hijo de Tomás de Rosende. Licenciado. Confirmado en el presbiterado por el obispo Mancha y Velasco en 1648. Cura de la catedral y canónigo en 1649.... Fue poseedor de: Una suerte de tierras para estancia, que me tocó en patrimonio, que están de esta banda del río de Luján.
}

12 Ibid., p. 322. 
antes debe ser castigado por el delito que cometió y vuéltolo a embarcar a su costa. Todo ello muestra las situaciones que se barajaban por una cuestión de competencia en los puestos del Cabildo, la administración pública y en el comercio. No obstante haber sido inculpado, el gobernador de Buenos Aires, don Francisco de Céspedes (1624-1631) lo apoyó, ordenando su liberación. Adujo que la acusación no era tal desde que había ya obtenido la residencia al casar con mujer de origen castellano (por tanto, vecina de la ciudad, descendiente de conquistadores de estas provincias) ${ }^{13}$.

Ocupó el cargo de procurador pocos días después, ejerciéndolo hasta el 3 de noviembre de 1625 , momento en que fue reemplazado por Juan Batista Ángel por tener una ausencia forzosa de la ciudad. Viajó al interior del territorio para cobrar unos créditos de su mujer, ausentándose en Potosí el 4 de mayo de 1625, para cobrar dichos créditos. En una época de grandes turbulencias políticas su fortuna aumentó por la cuantiosa herencia de su suegro y lo que logró adquirir por sí mismo. Con este dinero compró tierras y solares, llegando a contar con 27 esclavos (también se dijo 30), lo que da cuenta de su gran solvencia económica. Su vivienda en la ciudad, frente al Río de la Plata, lindó con la del maestre de campo Felipe Navarro ${ }^{14}$.

La figura del canario que nos comprende debió ser agradable y competente a muchos desde que al año siguiente volvió a ser elegido como procurador general: como persona más a propósito por haber usado el dicho oficio con puntualidad y cuidado, tomando posesión el 28 de febrero de $1626^{15}$, si bien el 4 de mayo solicitaba ya licencia. González Filiano falleció bajo poder testamentario el 18 de enero de 1645, ordenando su entierro en la iglesia de San Francisco en la peaña del altar de Nuestra Señora de la Limpia Concepción vestido con el hábito de hermano del santo ${ }^{16}$. Fue asimismo cofrade de San Sebastián

\footnotetext{
13 MOLINA, R. A.: Diccionario Biográfico de Buenos Aires..., op. cit., p. 321.

${ }_{14}$ Ibid., p. 321. Fue también propietario de cientos de hectáreas. Las obras escritas al respecto expresan que la merced que gozó González Filiano le fue otorgada desde el siglo XVII por el gobernador don Francisco de Céspedes (1629): estancia en la margen derecha del río Luján. De hecho, tanto la estancia de la dote de 1617, como la de 1629, tenían los mismos linderos (García Doctor y Diego de Trigueros, padre de doña Francisca).

15 Ibid.: pp. 321-322.

16 IBARGUREN, C. (h.): "González Filiano", art. cit., p. 115. En 1641 González Filiano hizo postura en el Cabildo a fin de abastecer de "carne de baca y ternera" a los habitantes de este puerto. Murió cuatro años más larde, bajo disposición testamentaría del 18-1-1645. En dicha escritura de última voluntad, el causante ordenaba se enterrara su cadáver amortajado con el hábito seráfico, en la iglesia de San Francisco, en el nicho de su familia [...], lo cual revela que en aquel tiempo se podian cometer delitos fiscales reiterados, sin mengua de una sincera devoción religiosa, sistemáticamente practicada y públicamente conocida. No obstante esta última afirmación del autor, ver las apreciaciones de la tesis de licenciatura en Buenos Aires: PERUSSE VERAS, M.: "Conductas y procedimientos fuera de la ley: comercio ilícito, líderes y prácticas". Universitas Humanística, n. ${ }^{\circ}$ 63, enero-junio de 2007, Bogotá, Colombia, 2007. <http://www.scielo.org.co/pdf/unih/n63/n63a11.pdf.>, pp. 203-239, donde dice: La acción politica tenía entonces -en el Antiguo Régimen - un aspecto esencialmente grupal porque buena parte de esta politica buscaba conseguir para si mismo o para parientes y allegados cargos directivos en los cuerpos y en los que produjeran los mayores beneficios o influencias. Incluso las acciones que a simple vista podrian parecer individuales se encontraban todas intimamente unidas a estrategias de grupo. Cada uno de los grupos que conformaban este tipo de
} 
y tesorero de la Santa Cruzada en 1644. Designó como albaceas a don Diego de Cospedal y Grimaldo y a su mujer, de la que en tal ocasión no aparece su nombre (D. ${ }^{a}$ Isabel Cabral de Melo ${ }^{17}$, viuda de Antonio Gouvea), y a Lucas Páez de Guadalupe.

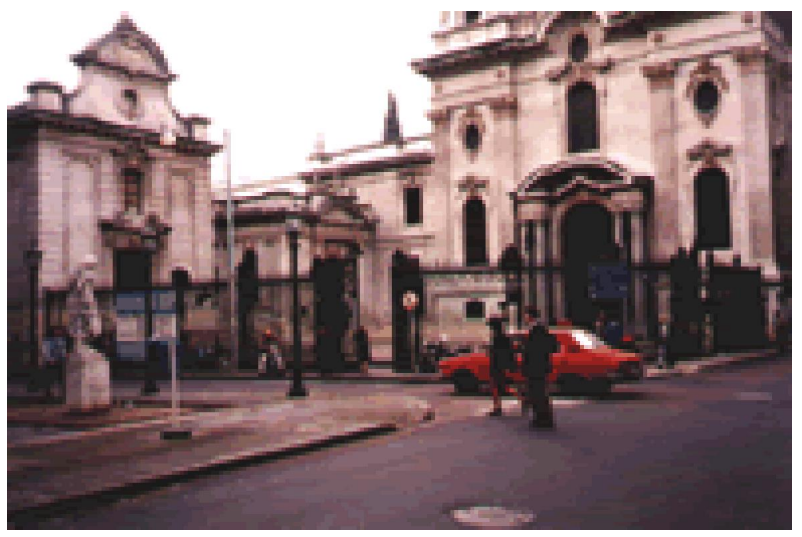

Figura 4: Iglesia de San Francisco, hoy basílica. En el costado izquierdo, la capilla de San Roque (Foto de la autora)

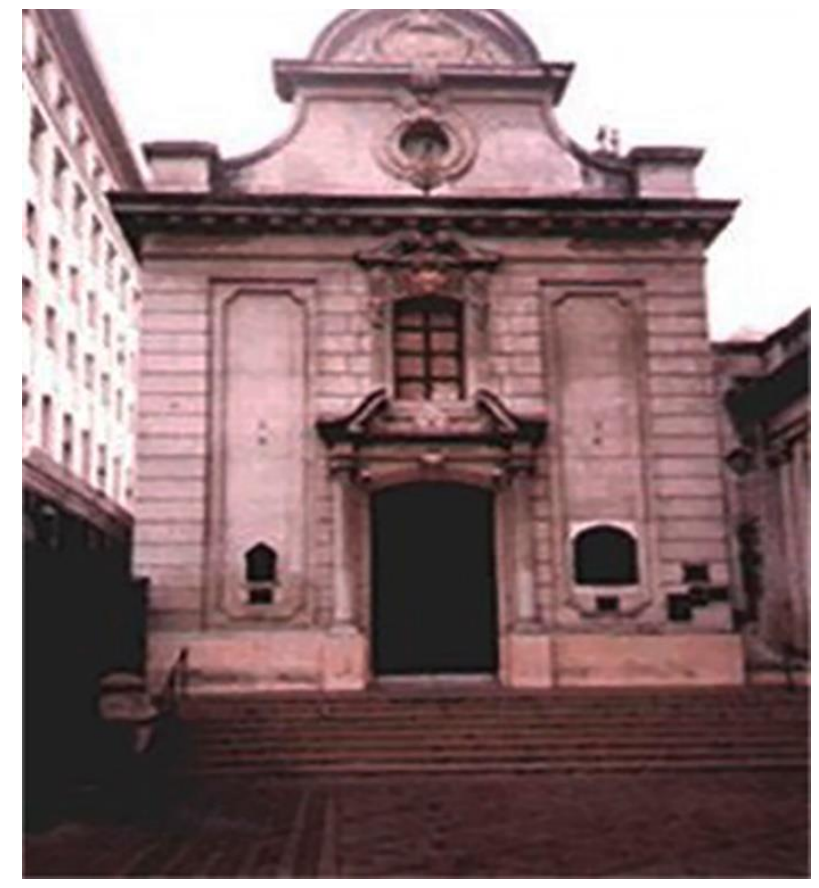

Figura 5: Capilla de San Roque de frente (foto de la autora)

sociedades tradicionales actuaba en función de preservar y acrecentar sus privilegios y su poder. También lo hacian para cubrirse frente a los ataques de los miembros de grupos opuestos (p. 221).

17 MOLINA, Raúl A.: Matrimonios, Bautismos y Defunciones de la Catedral de Buenos Aires, 1601-1644. Y legajos I y II de Expedientes Matrimoniales del Archivo del Arzobispado de Buenos Aires (Ex Curia Eclesiástica), Buenos Aires, Academia Americana de Genealogía, 2002, p. 119. D. Diego de Cospedal Grimaldo Risso (o Rizo) llegó a Buenos Aires procedente de Garachico, de donde era vecino. Había presentado información de viudez hecha en Tenerife. Testigos de la información para casar fueron Francisco Rodríguez, nacido en Viana, de 22 años; Martín Casado, del mismo lugar, de 40 años; y Antonio Montero, de Lisboa, donde había visto la luz, de 24. 
Notable resulta la cantidad de objetos suntuarios de su testamentaría, ya que además de tierras y casas poseía cuantiosas piezas de plata labrada, cuja de cortinas de brocado de seda, mesa de jacarandá y sillas de mano forradas, entre tantas otras prendas materiales. En su haber se observa también la posesión de 1.000 cabezas de ganado vacuno y un número mayor de lanares, cifras más que importantes. Como si ello fuera poco, fue propietario de cuatro chacras en la localidad de Montegrande (San Isidro), con casas con atahona moliente $y$ corriente ${ }^{18}$. A ello se sumaban siete estancias sobre el Luján y la Cañada de la Cruz (todo ello hoy en la provincia de Buenos Aires), tiendas y varias cuadras de terrenos en la ciudad (ver abajo mapa de la provincia de Buenos Aires y sus distritos).

Vale expresar que González Filiano estuvo relacionado con varios canarios y portugueses. Crónicas posteriores señalan la gran fortuna de este poblador canario. Se calculó que fue la tercera en importancia en Buenos Aires ${ }^{19}$.

Figura 6

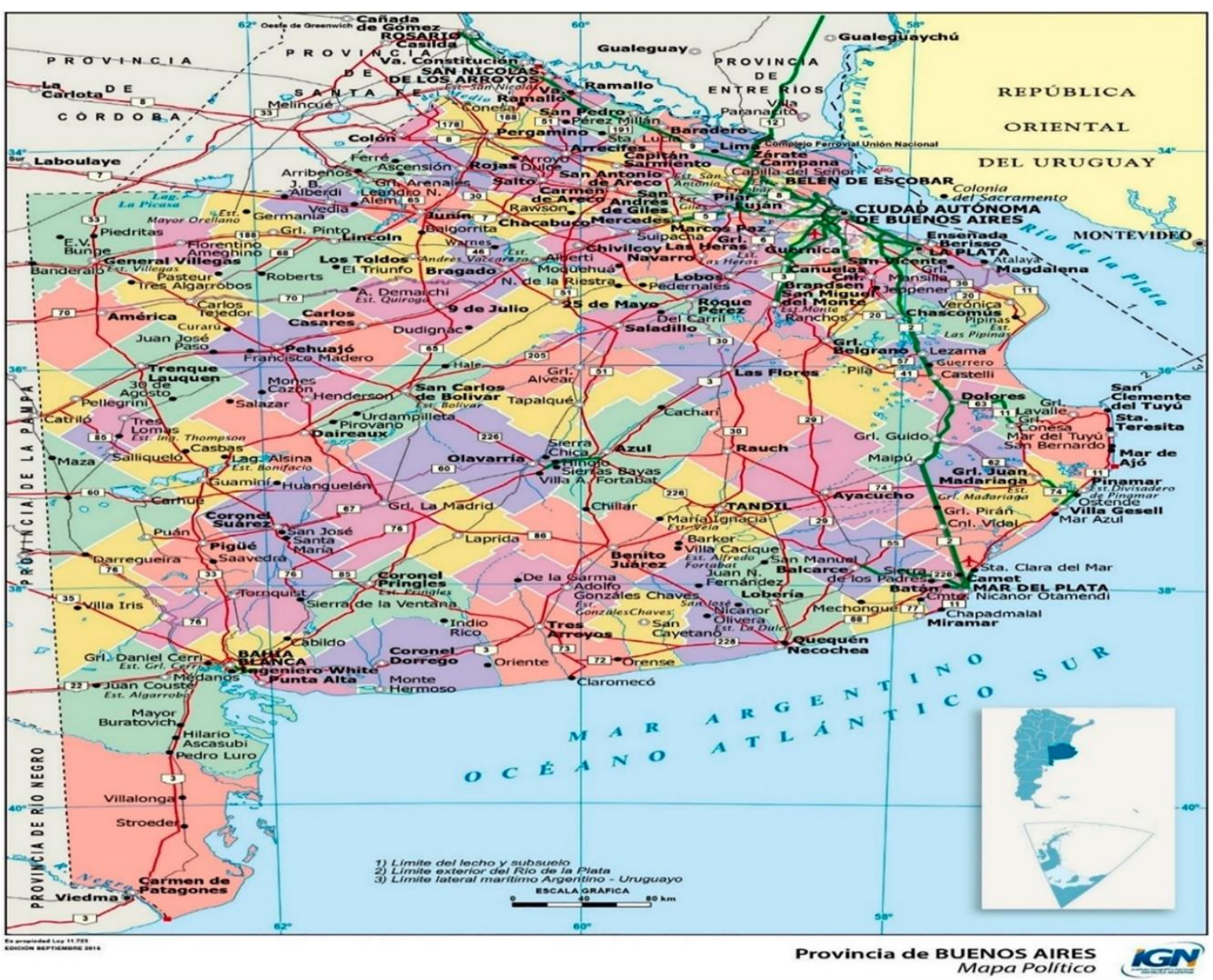

Mapa actual de Buenos Aires. En el noreste se encuentran algunas de las localidades en donde poseyó tierras B. González Filiano.

18 MOLINA, R. A.: Diccionario Biográfico..., op. cit., p. 322. A ello se sumaban siete estancias sobre el Luján y la Cañada de la Cruz, tiendas y varias cuadras en la ciudad.

19 CIORANESCU, A.: Diccionario Biográfico de canarios-americanos..., op. cit., vol. II, p. 917. Tenía una casa en Garachico, heredada de sus padres. 
Con respecto al apellido Oramas con que fueron conocidos sus hijos, el que provenía por la parte materna, Mencía Hernández de Oramas se sabe que tenía origen guanche:

Eso es de uno de los famosos héroes que resistieron a la conquista de los españoles, apellido que le pertenecía por su abuela paterna, luego usado por la mayoría de los descendientes de González Filiano ${ }^{20}$.

Sin querer entrar en la historia del que habría sido Doramas, héroe de origen indigena de interesante recuerdo que escapa a la narración del aquí tratado, se continúa con la vida de doña Francisca quien - se dijo- contrajo matrimonio con Bernabé González Filiano en 1622. Este actuó como padre del hijo del primer enlace de su esposa, cuyo nombre fue Diego de Rosende Trigueros, nacido en 1619, mejorado en su herencia por su abuelo Diego de Trigueros y Caro, en el tercio y remanente del quinto.

Uno de los hijos de Bernabé González Filiano y doña Francisca Trigueros fue el maestro Juan de Oramas y Filiano, quien usó también el apellido Trigueros, bautizado en 1629 en Buenos Aires, al igual que sus hermanos, ejerciendo como cura propietario de la catedral de dicha capital hacia $1671^{21}$. Asimismo, entre sus hijos mencionaremos a Magdalena, bautizada años antes, en 1625, que falleció infante; a Isabel de Oramas y Trigueros, nacida en 1629 (no sabemos si fue melliza de Juan o si los asientos parroquiales adolecían de defecto registral), casada con el alférez Juan Esteban Gámiz y Vergara; y a Basilia de Oramas y Trigueros, esposa de Diego Páez Clavijo y Vergara22. En estos registros los nietos llevaron el apellido de sus abuelos.

La descendencia de Bernabé González Filiano y doña Francisca de Trigueros continúa en la actualidad en la Argentina. Numerosos trabajos indican los apellidos que tienen como antepasados a esa pareja de notable ascendencia canaria $^{23}$, agregados una parte de ellos en el Anexo Documental. Al enviudar por segunda vez doña Francisca Trigueros figura en los documentos consultados anotada con 400 cueros, producto de su hacienda en campos, en la exportación de Gómez del Rivero ${ }^{24}$. Cabe destacar que dicho Diego de Rosende y Trigueros, su hijo, llegó a ser licenciado y clérigo, testigo principal de un milagro de la Virgen de Luján ${ }^{25}$, que habría presenciado un hecho que se recuerda aún en la actualidad.

\footnotetext{
20 Ibid., p. 322.

${ }^{21}$ Ibid., pp. 533-534. En 1668 fue promotor eclesiástico. Participó como miembro de la Hermandad del Santo Cristo. Falleció en noviembre de 1706 bajo poder testamentario dado a su sobrino Sebastián Ágreda de Vergara. Heredero de la estancia de Rosende y Trigueros y ubicado en Luján, donde se había producido años antes el milagro de la Virgen de Luján. Puso a su cuidado al negro Manuel, de larga trayectoria histórica. El que nos ocupa cedió sus derechos a doña Ana de Matos por la suma de 200 pesos, debido a los perjuicios que en su hacienda hacian los peregrinos.

${ }^{22}$ IBARGUREN, C. (h.): "González Filiano", art. cit., pp. 113-120. MOLINA, R.; Diccionario biográfico..., op. cit., pp. 321-322.

23 IBARGUREN, C. (h.): "González Filiano", art. cit., pp. 113-120.

${ }^{24}$ MOLINA, R. A.: Diccionario Biográfico..., op. cit., p. 322.

${ }^{25}$ CORTABARRÍA, Jorge Juan: "Raúl A. Molina y la historia de la Virgen de Luján", en Temas de historia argentina y americana, n. ${ }^{\circ}$ 6, Buenos Aires, Pontificia Universidad Católica Argentina, Facultad de Filosofia y Letras, enero-junio de 2005.
} 
El lugar en cuestión suscitó entre los siglos XX y XXI estudios complejos desde que primero existieron dudas de la verdadera zona donde ocurrió el milagro: la "estancia de Rosendo", de la familia de Bernabé González Filiano, casado con doña Francisca de Trigueros. Consta que desencadenó una verdadera fiebre religiosa en mérito al milagro ocurrido con la Virgen de Luján, advocación mariana. Es de expresar que al fallecer don Bernabé en el año 1645, la estancia del episodio pasó a administrarla primero su viuda, o su hijastro Diego Rosendo. De hecho, no se hace referencia al relato completo de la famosa Virgen de Luján venerada por sus milagros, porque excede este apartado. Sobre el particular puede aclararse que las carretas que trasladaron a dicha efigie mariana llegada al puerto de Buenos Aires pararon en la estancia del último, ubicada en la actual localidad de Pilar en el partido bonaerense, sobre la margen derecha del río Luján. Se ha repetido que los animales que la transportaban se negaron a seguir su camino, a pesar de todo lo que se hizo al respecto, quedando la Virgen para siempre en ese lugar ${ }^{26}$. En la actualidad existe a pocos kilómetros la construcción de la basílica homónima, en recuerdo de la Virgen de Luján ${ }^{27}$.

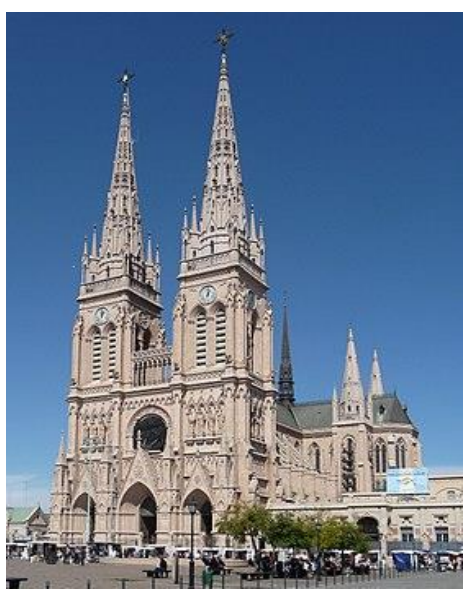

Figura 7: Basílica nacional de Nuestra Señora de Luján. Monumento histórico nacional argentino. Construida en 1890 a instancias del padre Jorge María Salvaire, se finalizó en el año 1935. En 1930 el papa Pío XI le otorgó el título de basílica menor (foto de la autora).

${ }^{26}$ MOLINA, Raúl A.: "Leyenda e historia de la Virgen de Luján". Academia Nacional de la Historia, Boletín n. ${ }^{\circ}$ XL, Buenos Aires, 1967, pp. 152. y ss.

[<file:/ / / C:/Users/Nora/Downloads/BaANH49338_Bolet\%C3\%ADn_de_la_Academia_ Nacional_de_la_Historia_XL_1967\%20(3).pdf>].

27 Wikipedia: «El origen de la advocación se remonta a 1630. Antonio Farías Sáa, un hacendado portugués radicado en Sumampa (actual provincia de Santiago del Estero, Argentina), quiso erigir en su estancia una capilla en honor de la Virgen. Solicitó a un compatriota suyo, residente en Brasil, el envío de una imagen de la Inmaculada Concepción de María. Para una mejor elección, su amigo le envió dos imágenes. En el mes de mayo de 1630, las imágenes de la Virgen llegaron al puerto de Buenos Aires procedentes de San Pablo y, acondicionadas en sendos cajones, fueron colocadas en una carreta. Luego de tres dias de viaje, la caravana a la cual se incorporó la carreta hizo un alto a 10 leguas de la actual ciudad de Luján, en el paraje de Zelaya, para pernoctar en la "Estancia de Rosendo" de Trigueros. Al día siguiente, ya dispuestos a continuar la marcha, los bueyes no consiguieron mover la carreta. Tras intentos fallidos, bajaron uno de los cajones y los bueyes iniciaron la marcha sin dificultad. Intrigados por el contenido del cajón, encontraron al abrirlo una imagen pequeña ( $38 \mathrm{~cm}$. de altura) de arcilla cocida que representaba a la Inmaculada Concepción. Los creyentes interpretaron el hecho como providencial y entregaron la imagen para su custodia a don Rosendo de Trigueros, el dueño de la casa ubicada en la actual Zelaya, partido del Pilar, a $50 \mathrm{~km}$ del actual emplazamiento del santuario. La segunda imagen, que representaba a María con el niño en sus brazos, llegó a destino, y en 1670 se le construyó un santuario donde se la veneró bajo la advocación de Nuestra Señora de la Consolación de Sumampa". 


\section{Simón de Valdez}

Sobre este canario se insertarán en el texto dos apreciaciones. La primera, la que surge de estudios puntuales realizados en Argentina sobre la base de gran cantidad de documentos. La segunda, la que proviene de un Diccionario de canarios radicados en América de A. Cioranescu ${ }^{28}$. Ello se debe a que las fuentes utilizadas son disimiles y aclaran en cierta forma aspectos nada conocidos del mismo. De tal manera, se procede a integrar los primeros aspectos relacionados con Valdez (o Valdés).

\section{a) Biografia de Simón de Valdés según las fuentes argentinas}

Simón de Valdez o Valdés, perteneciente a una familia ilustre, nació en la isla de Tenerife en el último cuarto del siglo XVI, pasando en esta región su juventud. Su tío, el Dr. don Juan de Llancos [Llanos] y Valdez llegó a la dignidad de obispo de León y fue consejero de la Inquisición (1616) ${ }^{29}$. Desde joven ocupó el cargo de teniente de capitán general de dicha isla de Tenerife. Pasó a América buscando abrirse nuevos rumbos como cabo de diez navíos y posó pie, primeramente, en la ciudad de La Habana. Se distinguió por su osadía y tal se dice: ... al frente de un navio persigue y derrota a un corsario inglés, a quien conduce prisionero ${ }^{30}$. Luego fue a México al frente de dos compañias, para volver a La Habana, en donde el gobernador le encomendó el mando de una flotilla con la que enfrentó y venció a los piratas que asolaban el mar Caribe. Fue aquí procurador de la ciudad ante la Corte. El Consejo de Indias lo designó para ser tesorero en Buenos Aires, por lo que obtuvo un nombramiento de S. M. C. el 29 de julio de 1605. Arribó al Río de la Plata el 27 de febrero de 1606 en la carabela San Antonio. Tomó posesión de su cargo el 13 de marzo, siendo aceptado por el Cabildo el 3 de abril.

Más que original resulta su vida. El gobernador Hernandarias lo propuso para tener la tenencia de la hacienda, lo que provocó serios problemas de competencia con otro poblador, Hernando de Vargas, amén de la oposición del Cabildo. Esa administración la ejerció durante un año hasta el 1 de enero de 1608. Debió dejar su designación al ser rechazado por el Consejo de S. M., dado que los oficios reales eran incompatibles con el ejercicio de otras actividades. Sin embargo, en épocas del sucesor en la gobernación, Diego Marín Negrón ${ }^{31}$, en sociedad con Juan de Vergara y Diego de Vega ${ }^{32}$ formaron un

28 CIORANESCU, A.: Diccionario biográfico..., op. cit., vol. II, p. 1.091.

${ }^{29}$ COMELLA GUTIÉRREZ, Beatriz: "Los nombramientos episcopales para la Corona de Castilla bajo Felipe III, según el Archivo Histórico Nacional: una aproximación". Hispania Sacra, n. ${ }^{\circ}$ LX, 122, julio-diciembre 2008, pp. 703-733.

[<http:// 62.204.194.45/fez/eserv/bibliuned:DptoHEEC-FEDU-Articulos-Bcomella7045/Comella_Beatriz_Nombramientos.pdf>].

30 MOLINA, R. A.: Diccionario Biográfico..., op. cit., p. 749.

${ }^{31}$ Ibid., p. 448.

32 Ibid., pp. 760-762. La biografia de Diego de Vega es rica en alternativas comerciales y por la ayuda que prestó a Simón de Valdez y a Juan de Vergara. Vega era de origen portugués nacido por el año 1570. Sus padres también eran naturales de la ciudad de Lisboa. Había entrado al Río de la Plata en su propio navio, San Antonio. Tratante de esclavos, llegó a poseer una inmensa fortuna. Contrajo matrimonio en su país en 1604 con una dama de alcurnia: doña Blanca de Vasconcellos. Volvió a Buenos Aires en 1607. En 1610 obtuvo licencia para 
grupo para activar el comercio del contrabando ${ }^{33}$. Se debe recordar el nombre anterior de Juan de Vergara, quien era pariente político de Bernabé González Filiano.

La documentación recoge que Simón Valdez llegó a ser principal propulsor del contrabando, lo que continuó con otro sucesor de Marín Negrón, Mateo Leal de Ayala. Se dijo que el primero no reparó en enmendar su conducta deshonesta hasta el punto de que, esperando un cargamento de contrabando de esclavos, se metió en el Río de la Plata esperando la llegada del barco con las piernas en el agua, a altas horas de la noche para hacerlos pasar en secreto, al margen de la ley. Sobre dicho tesorero se indicó:

En todos los navios que entraron, el tesorero Simón de Valdez, cuando iba a visitarlos, apartaba a los maestres y les hablaba al oido [...] y oyó decir muchas veces al dicho tesorero, a los dichos maestres y cargadores, que le llevasen mercaderias, de ropa lienzo, vino y otras cosas. Y se las vio llevar este tesorero muchas veces a la dicha su casa ${ }^{34}$.

No ha sido posible conocer con quién contrajo matrimonio en Canarias, pero sí que sería viudo al llegar más tarde a Buenos Aires, luego de un largo periplo, con su concubina, de nombre Lucía González [de Guzmán], sobre lo que se aclaró: con quien hace vida marital en público ${ }^{35}$. Según las obras literarias, fue mujer de fuerte personalidad, que pronto se acostumbró a grandes lujos haciéndose portar por la ciudad con sillas de varas labradas, con estrado, cojines, acompañaba por un grupo de sirvientes ${ }^{36}$.

Al arribar el gobernador Hernandarias a Buenos Aires para ejercer una nueva gobernación ${ }^{37}$, descubrió los delitos del tesorero, por lo que mandó colocarlo en prisión el 29 de mayo de 1609 junto a Mateo Leal de Ayala, el ex

traer a esta ciudad a su familia, la que ingresa el 14 de noviembre de 1613. La esposa sobrevivió hasta el año 1623, año en que dio disposición testamentaria el 6 de febrero ordenando su entierro en la capilla mayor de la iglesia de San Francisco en Buenos Aires. Recibió en arras 10.000 ducados de su esposo, quien se dedicó de manera continua al comercio ilícito. Hernandarias dijo de Diego de Vega: mercader portugués que favorece, ayuda y apoya a los demás que trajinan, el cual ha venido ha treinta años, que trata y contrata en este puerto y tiene correspondientes en Flandes, Portugal, Brasil y el Perú, que es compadre del dicho justicia mayor [Leal de Ayala], y amigo intimo y compañero del dicho tesorero ([Simón Valdez], y reside en este dicho puerto con su mujer y familia.

33 Para ampliar el tema, véanse las obras de MOUTOKIAS, Zacarias: "Burocracia, contrabando y autotransformación...", art. cit.; id: "Contrabando y sector externo...", art. cit.

34 PERUSSE VERAS, M.: "Comportamientos al margen de la ley: contrabando y sociedad en Buenos Aires en el siglo XVII", Historia Crítica, n. ${ }^{\circ} 33$, Bogotá, enero-junio de 2007, p. 172.

35 MOLINA, R. A.: Diccionario Biográfico..., op. cit., p. 750. Se debe matizar que esta frase del autor debe entenderse en el contexto de una sociedad estricta en cuanto a las formas religiosas, que veían mal dichas relaciones.

36 MONTES-BRADLEY II, Saúl M.: Hidalgos, Marinos y Conquistadores. Los Montes del Caballito, sus ancestros y descendencia, South Boston, Virginia, 2014, p. 213. Se señala: Doña Lucía González de Guzmán. Nació en Madrid, España, llegó a Buenos Aires en febrero de 1606, como amante del capitán Simón de Valdez, tesorero de la Hacienda Real de Buenos Aires, quien la conoció en Madrid cuando era "camarera de palacio".

37 MONTES-BRADLEY II, Saúl M.: Hidalgos, Marinos y Conquistadores..., op. cit.; TORRE REVELLO, José: "Los Gobernadores de Buenos Aires (1617-1777)", en LEVENE, Ricardo (dir.): Historia de la Nación Argentina (desde los orígenes hasta la organización definitiva en 1862), Buenos Aires, Editorial Ateneo, 1939, vol. III. 
justicia mayor Juan de Vergara, Diego de Vega y Gaspar de Azevedo (este, escribano de la ciudad). Comenzó a hablarse de ellos, debido a su accionar e importancia, como los que componían en el Río de la Plata el "cuadrilátero" de comercio ilegal.

Entre las serias acusaciones se imputó a Valdez como envenenador del exgobernador Marín Negrón, la extorsión a algunos pasajeros clandestinos, el establecimiento de tablas de juegos en su casa, el concubinato citado. Como si fuera poco, se descubrió una famosa estafa realizada a los vecinos de Río de Janeiro: el préstamo y utilización de los dineros reales para la negociación de los remates y compras de esclavos, además de una verdadera multitud de causas menores por tratos antilegales que ejerció con los mismos ${ }^{38}$. De hecho, más allá de la certeza de las denuncias contra él, lo cierto es que Simón Valdez tuvo muchos enemigos.

Los cargos fueron graves. En esas circunstancias, Hernandarias decidió enviarlo engrillado a España en marzo de 1615, a bordo del navío Nuestra Señora de Monserrate, al mando de Hernando de Rivera y Mondragón. Extorsionado este último y contraviniendo el mandato del gobernador Hernandarias, recaló en Río de Janeiro, donde Valdez logró su libertad. En esta región levantó informaciones y, por sí mismo, se dirigió a España, donde se presentó en la cárcel de Madrid, lugar en que todavía estaba el 15 de marzo de 1616. No se conoce a ciencia cierta con qué argumentos se manejó, lo cierto es que fue absuelto de la prisión, consiguiendo ser repuesto en el cargo con fecha 7 de febrero de 1617. En el interin de estos hechos, trabó relación con el nuevo gobernador de Buenos Aires, Diego de Góngora y Elizalde (1618-1623), y de común acuerdo resuelven en Lisboa introducir un grandioso contrabando en mercancias que, al fin, después de infinitas aventuras logran introducir en Buenos Aires el 18 de noviembre de $1618^{39}$.

Es de señalar que, en vinculación con los episodios ocurridos con que se manejó Simón de Valdez, actuó como testigo respecto al canario D. Bernabé González Filiano, sobre quien se dijo:

El 4 de diciembre de 1618, en la "Información" ofrecida por el tesorero Simón de Valdés a fin de probar que en la causa criminal emprendida contra él bajo la dirección de Hernandarias los testigos habian declarado movidos por el interés o el temor, compareció Bernabé González Feliano [sic], residente en Buenos Ayres, natural y vecino de la isla de Tenerife, el cual dijo ser de treinta y cuatro años, poco más o menos; $y$ aunque ha sido pesquizado en esos autos del contrabando, no le tocan las generales de la ley. Afirmó el deponente que en la pesquiza contra Valdés y otros, incoada ante el actuario Juan de $\mathrm{Mu}$ narriz, el vecino Antonio Linares le persuadió declarase, haziéndole promesas que si lo hazía lo faborecía el governador Hernandarias de Saavedra... e si no jurava a este testigo y los demás les iría mal, dando a entender se les haria grandes castigos, como después se vio en los tormentos que se dieron a diferentes personas. También, el 5

38 MOLINA, R. A.: Diccionario Biográfico..., op. cit., p. 750.

39 Ibid., p. 750. 
de noviembre de 1619, en el proceso que contra el gobernador Diego de Góngora llevó a cabo el juez pesquisante licenciado Matías Delgado Flores, compareció ante el escribano Domingo Fuentes, Bernabé González Fiolian [Filiano] [sic]. En tales actuaciones mi antepasado figura como "morador en la ysla de Tenerife, que dixo hacía algunos días que estaba en esta ciudad". Declaró frizar en los 34 años, aproximadamente, y que conoció a Góngora cuando este funcionario llegó a Buenos Aires en el mes de noviembre de 1618, en circunstancias en que el declarante "estaba preso en la cárcel pública por mandado del gobernador Hernandarias" 40 .

La complicada existencia de Valdez tuvo variados acontecimientos: ya repuesto en el cargo de tesorero en la ciudad, emprendió viaje a Potosí a fines de 1618 para vender un valioso cargamento de esclavos. En esta ocasión fue denunciado por los oficiales de S. M. de ese lugar. Al pretender volver a Buenos Aires se enteró de la presencia de un juez pesquisidor nombrado por el Real Consejo con la orden de prenderlo y llevarlo de vuelta a España. Ello motivó que se dirigiera a Tucumán, pero con todas las salidas vigiladas huyó en dirección a La Rioja, en el noroeste de la actual Argentina, con la idea de pasar a Chile. Aquí sus rastros se pierden y es posible que no llegara a territorio chileno. Circunstancia que, en realidad, no se pudo comprobar, tal como se expresa en el segundo de los apartados sobre su biografia.

En efecto, estaría implícito que consiguió regresar a Canarias luego de sortear una cantidad de graves situaciones y falleció en torno a 1644. Antes de emprender aquel viaje, redactó en Tucumán un testamento, en el que reconoció hijos habidos en dos casamientos. Se cree que entregó a su albacea Graneros de Alarcón gran parte de sus bienes. No se entiende bien la frase que se asentó al respecto: y esa es la razón por la cual cuando muriera Alarcón, pudiera testar ${ }^{1}$.

Fue progenitor —entre otros- de Simón Valdez, el Mozo, concebido también en Canarias, con quien había viajado a Buenos Aires en el año 1606. La conducta posterior de este último revela la antítesis del que lo concibió. Sabemos que se enroló en el ejército en la guerra de Chile con brillante actuación. Sin embargo, sus pasos posteriores lo encuadran como figura inquieta, perseguido por varios enemigos y en continuas fugas, sin conocerse nada de su vida posterior al decidir embarcarse a España ${ }^{42}$. Asimismo consiguió fugar a España desde una región actual de la provincia de Buenos Aires (Fontezuelas), al ser conducido preso por el oidor Pérez de Salazar, quien fue gobernador interino del Río de la Plata entre 1623-1624.

Si se vuelve años atrás, Simón Valdez, en su estadía en Buenos Aires se granjeó desde tempranas épocas varios enemigos. Estudios puntuales sobre tres letrados coloniales que deseaban instalar sus bufetes en la ciudad indican que al principio empleó toda su influencia en 1613 para que no fueran aceptados. Estos abogados eran Gabriel Sánchez de Ojeda — venía de Chile—, José

40 IBARGUREN, C. (h.): "González Filiano", art. cit., p. 114.

${ }^{41}$ MOLINA, R. A.: Diccionario Biográfico..., op. cit., p. 750.

42 Ibid., p. 749. 
de Fuensalida y Meneses de Córdoba en territorio rioplatense; además de Diego Fernández de Andrada, de Santiago del Estero, de esta última gobernación. Más tarde, sólo José de Fuenzalida tuvo tratos que lo relacionaron con Valdez.

De hecho, el propio Cabildo había tomado la decisión de no permitirles la entrada, según el relato existente ${ }^{43}$, pero fue el tesorero de su majestad, Simón de Valdez, quien declaró: no era menester letrados, porque los que han venido a ella solo han servido para inquietar a los oficiales reales con los gobernadores, y a todos los demás vecinos del pueblo. Se observa en esta expresión que los propios intereses quedaban recelados ante la posibilidad de tener futuros letrados que intervinieran en sus asuntos.

Toda una historia local se desarrolló en torno de estos episodios. Los documentos afirman que el gobernador Marin Negrón había decidido visitar los navios de registro que arribaban, lo que efectuaba sin la presencia de letrados y del Tesorero:

El gobernador les respondia que estas visitas eran ya costumbre desde los tiempos de Fernando de Zárate y de Hernandarias, "y si este que era hombre criollo y de tan poca luz de negocios, lo habia hecho asi, era muy justo que él no sólo conservara el procedimiento, sino que aún le excediera en esto" 44.

Como si las diferencias fueran menores, Valdez apoyó a Marín Negrón, recomendando se diera azotes a los que no aceptaban las condiciones: [...] porque este gobernador tiene y muestra ganas de acertar ${ }^{45}$.

Poco tiempo duró esta vinculación. En efecto, a la muerte de Marín Negrón, acaecida el 26 de junio de 1613, el famoso "cuadrilátero" contrabandista se había apoderado del gobierno de la ciudad, integrado por el justicia mayor en ejercicio, Mateo Leal de Ayala, el tesorero Valdez, y los capitanes Juan de Vergara (alcalde ordinario), y el más que rico portugués Diego de Vega. Todo esto ocurría en Buenos Aires, considerado por entonces un puerto importante.

En momentos en que Hernandarias se hizo nuevamente con el cargo de la gobernación -ya que fue nominado en diferentes oportunidades, esta vez en mayo de 1615-, quedaron a las claras las artimañas de los cabildantes contra los abogados, sucesos que remontan lo acaecido en Buenos Aires a 1613. Sin duda, los pretextos, en especial los de Valdez, encubrian las maniobras en el

43 CUTOLO, Vicente Osvaldo: "Abogados criollos en el Buenos Aires del 1600». Cfr.: $<$ https: / / bibliotecavir-

tual.unl.edu.ar:8443/bitstream/handle/11185/3571/RU023_09_A007.pdf>.

El Cabildo de Buenos Aires realizó una importante sesión el 22 de octubre de ese año, discutiendo seriamente el caso. Miguel de Corro, uno de los vecinos fundadores de la ciudad, regidor del cuerpo, expresó entonces que aquellos abogados se habian concertado para "venir a este puerto con el ánimo de que haya pleitos para ganar plata". Agregó que la experiencia había mostrado el daño que ellos producian porque no faltan pleitos, tramas, marañas $u$ otras disensiones, de que han resultado a los pobres vecinos y moradores desinquietudes, gastos y pérdidas de hacienda. Pedía, finalmente, que se les negara la licencia de entrada, fundado en que esta tierra era de frontera y no tenía necesidad de letrados.

44 Ibid.

45 Ibid. 
comercio de contrabando que les permitía acrecentar sus fortunas. Al respecto se dijo:

Todo esto se desprende del famoso proceso que en ocho mil fojas se encuentra actualmente en el Archivo de Indias. Figuraba como cabeza del mismo un cargo contra las autoridades de nuestra ciudad, bien significativo por cierto, cual era "de haberse atrevido", nada menos, "para que no entrasen letrados, ni fueran recibidos en la dicha ciudad, y que si entrase alguno o algunos, fuesen echados y desterrados" 46 .

En las maniobras empleadas en los delitos se conoció también el préstamo que se hizo de los dineros reales. El que antaño había sido expulso, abogado Gabriel Sánchez de Ojeda, comenzó entonces asesorando a Hernandarias en la mencionada causa. No extraña, por consiguiente, las penas que tiempo después se impusieron a Simón de Valdez para que fuera encarcelado, puesto con grilletes y enviado a España para limpiar sus acusaciones. La peor de ellas, la de instigador del envenenamiento del gobernador Diego Marín Negrón ${ }^{47}$.

Para finalizar esta primera parte de la existencia del canario que nos ocupa, se expresó la manera en que regresó a Buenos Aires con el gobernador Diego de Góngora, luego de haber pasado por España. En Potosí, involucrado en negocios de ventas de esclavos - de cuya especulación logró la enorme suma de 60.000 pesos-, fue denunciado por los oficiales reales de dicho lugar, por lo que huyó a Tucumán y pasó a La Rioja con la idea de seguir a Chile. En esta huida, desapareciót8 ${ }^{4}$. Análisis complementarios, como los que surgen del Diccionario de Canarios en América ${ }^{49}$, llevan a interpretar lo que efectivamente ocurrió. En un personaje dispuesto a todo, su emocionalidad y capacidad de acción permiten quede la duda de lo ocurrido. En sintesis: ¿realmente murió en el cruce hacia Chile o consiguió arribar de vuelta a España y al lugar de su

\footnotetext{
46 Ibid.

47 Ibid., pp. 203-204; Real Academia de la Historia (España): Diccionario biográfico electrónico [<http:/dbe.rah.es/biografias/11670/diego-marin-negron>]; QUINTANA BERMÚDEZ DE LA PUENTE, Covadonga: Marín Negrón, Diego. Málaga, 1560-Buenos Aires (Argentina). La información es la siguiente: 26.VII.1613. Gobernador y capitán general de Paraguay y Río de la Plata: "El 16 de agosto de 1608 Felipe III designó a Diego Marín, sargento mayor en aquel momento, como sucesor de Hernando Darias en el gobierno de las provincias de Paraguay y Río de la Plata. Llegó a La Trinidad el 22 de diciembre de 1609, acompañado de su médico, Juan Escalera, y presenció la segunda corrida de toros que se celebró en la plaza de Mayon. Es de destacar que a su llegada se relacionó al gobernador con el sevillano Juan de Vergara, familiar de B. González Filiano. Vergara fue uno de los principales cabecillas del tráfico ilícito, conjuntamente con Diego de Vega. Por momentos se vinculó a Marín Negrón con el contrabando, pero luego de tener grandes altercados con el grupo de los del "cuadrilátero", [este último] falleció repentinamente en 1613. Se organizó una comisión desde la Real Audiencia de Charcas para verificar el fallecimiento, comisionando a Enrique Jerez, quien "... descubrió que este personaje habia sido asesinado probablemente, y que el principal instigador habia sido Juan de Vergara, ya alcalde del Cabildo, que había contado con la colaboración de Simón de Valdez». Dicho Jerez fue después encarcelado. En estas circunstancias, el rey designó de nuevo a Hernando Arias de Saavedra como gobernador de las provincias de Paraguay y Río de la Plata para aclarar los hechos.
}

48 MOLINA, R. A.: Diccionario Biográfico..., op. cit., p. 750.

${ }^{49}$ CIORANESCU, A.: Diccionario biográfico..., op. cit., vol. II. 
nacimiento?50. A continuación, se incorporan algunos datos poco conocidos sobre su vida.

\section{b) Biografia de Simón de Valdes según las fuentes canarias}

Según A. Cioranescu, Simón de Valdés [sic] era natural de Tenerife, hijo de otro Simón de Valdés y de Clara Hemerando. El padre del primero testó el 16 de octubre de 1577, declarando ser vecino de Sevilla, de manera que el señalado en primer lugar habría nacido hacia 1565. Se casó el 3 de mayo de 1582 en La Palma con Magdalena de Miranda, hija de Lesme de Miranda y de María de Lezana ${ }^{51}$, y arribó a Buenos Aires en 1606 por la designación del gobernador del Río de la Plata, Hernando Arias de Saavedra, conocido sólo como Hernandarias, del que recibió el cargo de teniente general del gobernador. Se deja ver que hasta aquí las fuentes, tanto de Argentina como de Canarias, son similares en cuanto a la fecha de su llegada en 1606 al Río de la Plata.

Más tarde, Simón de Valdes fue juez oficial real de la provincia hasta 1615 y alguacil mayor del Santo Oficio de La Plata en 1614. Es destacable el hecho del que hablan los documentos. En efecto, de regreso a La Laguna se ordenó clérigo presbitero y fue capellán del Hospital de Dolores. En una extrema pobreza debido al ataque sufrido por piratas berberiscos (sufriendo dos años de cautiverio), cuando tenía poco más o menos 60 años de edad, su destino parecía derrumbarse. No obstante, por entonces, el arzobispo de Granada, Fernando de Valdés [y Llanos], reconoció en él a su pariente, uno de su estirpe y le rescató como deudo, pero al llegar a España, ya había fallecido el arzobispo. Extraño destino para quien había sido un hombre de fortuna en el Río de la Plata; sin duda, debió sufrir mucho en su cautiverio.

Figura 8: Retrato de Fernando de Valdés y Llanos

(1575-1639),arzobispo de Granada. Pintura de Velázquez, ca. 1640

[<https://es.wikipedia.org/wiki/Fernando_de_Vald\%C3\%A9s_y_Llano>, The National Gallery de Londres].

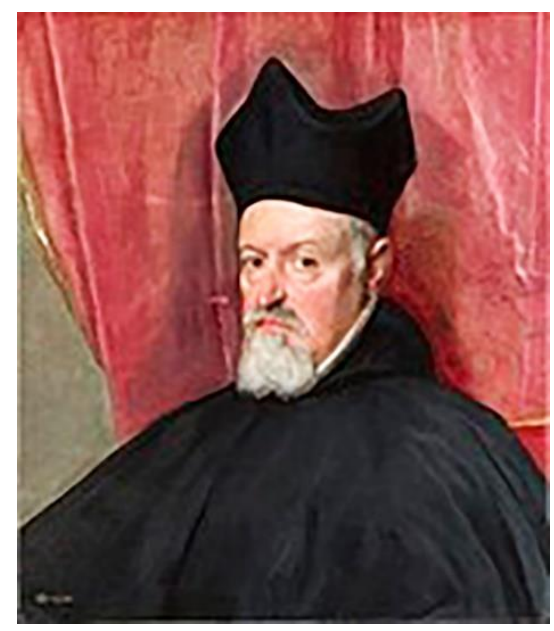

50 Ibid., vol. II.

${ }^{51}$ Ibid., vol. II. El padre de Simón de Valdés dio al primer marqués de Lanzarote, don Agustín de Herrera, una fianza de 18.000 ducados, que el marqués no devolvió. Por este motivo el hijo (el que tratamos) puso pleito en la Real Audiencia de Canarias, que le reconoció su derecho. En 1597 él tomó posesión del estado de Lanzarote. Sin embargo, el proceso quedó estancado, por no saber decidir si Lanzarote era mayorazgo o no. La mujer de Simón Valdés murió luego de haberle dado dos hijos: Simón (el tercero), bautizado en El Sauzal el 6 de octubre de 1592, y Diego, en La Laguna, el 26 de marzo de 1598. Según el Diccionario tratado: Él recibió el nombramiento de teniente general del gobernador del Río de la Plata, Hernando Arias de Saavedra (1606-1607). 
Poco tiempo después, la Real Audiencia de Canarias recomendó que se le nombrase maestre de escuela en Gran Canaria, pero la proposición no dio resultado $^{52}$. Finalmente, Valdes falleció en La Laguna en 1644 con aproximadamente 79 años (de corresponder esta información con lo asentado por A. Cioranescu), luego de otorgar testamento ante Simón Fernández Villarreal. Tuvo una hija, a quien dotó: Clara de Castilla, mejorada por escritura otorgada en Buenos Aires el 5 de junio de 1614, la que contrajo enlace con Simón García de Castilla, maestre de campo y regidor de La Palma. De hecho, en la biografia escrita en Canarias existen tres Simón de Valdes: el padre, el hijo y el nieto, todos homónimos. El arribado a Buenos Aires fue el segundo de ellos: Simón de Valdés (en otras versiones: Simón de Valdez).

\section{Conclusiones}

Una tesis de licenciatura rendida en la Universidad de Buenos Aires analizó desde el punto de vista histórico-antropológico la actitud de comerciantes con el contrabando. Ello presenta un enfoque original en cuanto a la conducta de muchos de los que participaron desde que, en medio del contexto político y económico desarrollado por una amplia mayoría de vecinos y extranjeros, aquella se integró en una explicación novedosa. En efecto, la misma reconoce una multiplicidad de causas en donde las actitudes de los sindicados como contrabandistas no deben entenderse con los conceptos actuales.

De hecho, el combate por los puestos del Cabildo y de la administración que poseían los "beneméritos", discutidos por los "confederados", fue una etapa de lucha de los primeros que no querian ser desplazados de sus prebendas y demás bienes obtenidos, como fue el usufructo de las encomiendas que poseían desde la época de la conquista.

No es nuestro interés indagar en estos acontecimientos y sí dar cuenta de la vida y actitud de canarios que arribaron a nuestro suelo. En realidad, puede decirse que González Filiano pasó a pertenecer por casamiento al grupo de los antiguos pobladores, apañado sin duda por un entorno de parentesco con contrabandistas, tan en uso y en boga del comercio de la época, como fue el caso de otro canario: Simón de Valdez. Estos hombres pertenecían a antiguas familias isleñas habituados a manejar empresas de comercio, además de poseer un original capital que supieron explotar, característica que se dio con énfasis en el segundo como especial tratante de esclavos.

El desplazamiento de los "beneméritos" por los "confederados" se produjo de a poco, integrándose estos en la sociedad y el comercio prohibido o ilegal, es decir, sin pagar los derechos de aduana - "impuestos"-correspondientes. Es de recordar que, salvo pocas excepciones, hasta los propios gobernadores elegidos por S. M. C. participaron del contrabando, ora sancionándolo, ora actuando a su favor con los que lo realizaban. Un caso de no integración y de respeto a las leyes de la Corona fue la que protagonizó en diferentes gobiernos el señalado gobernador Hernandarias. Téngase en cuenta que desde 1594 el monarca había convertido a Buenos Aires en un puerto cerrado, abriendo más

52 Ibid., vol. II. 
que nunca las expectativas de los comerciantes de Sevilla y Lima, en mérito a lo aconsejado por el virrey del Perú.

En síntesis, Bernabé González Filiano, oriundo de Garachico, fue un hombre culto que algo después de su llegada al Río de la Plata contrajo matrimonio con una descendiente de los conquistadores, es decir de los "beneméritos", como la historiografia los reconoce. Fue un hombre que ocupó cargos importantes en la ciudad, como procurador, si bien más tarde esto no lo exceptuó de llegar a la cárcel, como cuando estuvo preso por orden del gobernador Hernandarias. Tuvo negociaciones poco claras en el comercio y el contrabando en el puerto de Buenos Aires. Consta que favoreció las funciones religiosas, impuso capellanías y participó en varias cofradias. Tanto él como su esposa, doña Francisca Trigueros, solicitaron ser sepultados bajo el altar mayor de la Virgen de Nuestra Inmaculada de la Limpia Concepción en San Francisco de Buenos Aires, vestido con hábito de hermano franciscano, lugar de sepultura de los antepasados de la última.

Los actuales escritos de un historiador y genealogista, uno de sus descendientes Carlos Ibarguren (h.), dieron a conocer la enorme familia que ese matrimonio dejó en el Río de la Plata y en el actual territorio argentino, sucesión que continúa en la actualidad. Los hijos de los que nos ocupan fueron asimismo conocidos con el apellido Oromás, perteneciente a una abuela del canario González Filiano.

Por su parte, Simón de Valdez, nacido en Tenerife, estuvo siempre involucrado en el contrabando, provocando situaciones de conflicto hasta el punto de que, encadenado, se lo envió a España por el gobernador Hernandarias. Se dijo que consiguió en Brasil escapar al recalar el barco que lo transportaba, luego de haber comprado tal decisión al capitán. En una actuación de amplia especulación cambió en Madrid a su favor todas las imputaciones con que dicho Hernandarias en Buenos Aires lo había acusado, incluyendo su participación en el asesinato del gobernador Marín Negrón. No se conoce cómo logró revertir su sentencia, pero en 1618 regresó para continuar con sus negocios. Así las cosas, fue apadrinado por el nuevo gobernador del Río de la Plata, Diego de Góngora, con quien participó en cargamentos ilegales (entre otros) de tráfico negrero.

Llegó al Río de la Plata con una mujer — su amante-, luego de enviudar de su esposa en Canarias, viviendo ambos con gran boato. Al tratar de huir desde Tucumán hacia Chile en uno de sus manejos contrabandistas, se pierde su rastro. Tuvo un hijo habido en el archipiélago canario que llegó con su padre a Buenos Aires en 1606, llamado Simón de Valdez el Mozo. Este participó como militar en Chile. Fue un activo integrante del grupo de los "confederados", por lo que no extraña que acusara a Hernandarias con cargos graves. No obstante las denuncias, estas no prosperaron. Finalmente, el último fugó a España desde una región actual de la provincia de Buenos Aires (Fontezuelas).

Estas semblanzas de las páginas precedentes han intentado recordar la actuación -en especial - de dos canarios en su paso por el Río de la Plata, y de otros más que no alcanzaron la envergadura de los nombrados. González Filiano tuvo perpetuidad en la historia argentina desde que sus descendientes llegan a nuestros dias. Sobre los homónimos Valdés en el Río de la Plata no 
se conoce mucho más. Es posible que tanto el padre como el hijo (el Mozo) fueran personas muy reconocidas en Canarias.

El que atrajo la atención por su vida azarosa, Simón de Valdes o Valdez, fue un hombre que vivió entre dos mundos, al parecer entre 1595 a 1644, en lugares opuestos del océano Atlántico, en una verdadera odisea de sucesos desde que llegó a estar cautivo, siendo rescatado por un tío arzobispo de Granada. Sobre el hasta aquí tratado, bien valdria recobrar completamente sus andares en una novela histórica ${ }^{53}$.

\title{
ANEXO DOCUMENTAL
}

\section{Apellidos actuales en Argentina descendientes de D. Bernabé González Filiano.}

\begin{abstract}
Gonzalez Füliano
119

POST ANNOTATIO

Descienden de GONZALEZ FILIANO - por tanto de remotisima sanyre "guanche"-., entre muchas otras, las siguientes familas argentinas: Paez de Clavijo Trigueros Filiano; Ramirez de Sagies Paez de Clavijo: Rospigliosi Ramirez de Saguies; Gomez del Canto Rospigliosi; Gomez Rospigliosi; Gomez Ob]igado; Gomez Ibañez; Gomez Langenheim; Gomes Basaldua; Gomez Aguirre; Saguier Gomez Aguirre; Piñeiro Pearson Gomez Aguirre; Elía Gomez Aguirre; Quirno Gomez Aguirre; Jacobs Gomez Aguirre; Moreno Hueyo Gomez Aguirre; Lastra Gomez Aguirre; Tiscornia Lastra; Gomez Pombo; Gomez Seeber Demaría; Saenz Valiente Gomez Seeber; Guemes Ayerza Gomez Seeber; Obligado Gomez; Obtigado Nazar Anchorena; Schoo Obligado; Dosse Obligado; Zemborain Dosse; Dietrichs tein Dosse; Rospigliosi Ibañez Garcia de Roca; Ibañez Rospigliosi Marin de la Quintana; Anchorena Lopez Anaya Ibañez Marín; Aguirre Lajarrota Ibañez Marin; Anchorena Ibañez Aguirre Ibañez; Nazar Yaniz Anchorena Aguirre: Nazar Anchorena; Anchorena Aguirre Pico; Anchorena Arrotea; Beristayn Anchorena; Aldao Ocampo Beristayn Anchorena; Calvo Ancho mena: Anchorena Maschwitz; Anchorena Arana Aguirre Ibañez; Paz Portuguez Anchorena Aguirre; Madariaga Pirán Anchorena Aguirre; Urquiza Illa Anchorena Aguirre; Fernandez Torres Anchorena Aguirre; Castellane Fernandez Anchorena; Paz Anchorena Bustamante; Paz Anchorena Pearson Ouintana; Bustos Morón Madariaga Anchorena; Urquiza Anchorena Atucha; Urquiza Anchorena Marin; Quesada Pacheco Urqujza Anchorena: Bunge Arteaga Urquiza Anchorena; Urquiza Anchorena Oliveira Cesar; Uxquiza Anchorena Gowland Peralta Alvear; Urquiza Anchorena Hume; Lagos Mármol Urquiza Anchorena; Nazar Anchorena Ouesada Urquiza; Basch Quesada Urquiza; Urien Quesada Urquiza; Arrillaga Harilaos Urquiza Marín; Balcarce Urquiza Anchorena; García Fernández Urquiza Anchorena: Schindler Rosa Bunge Urquiza; Schindler Bunge Del Carril Sole: Schindler Bunge Sastre Sojo; Schindler Bunge De la Barra Lozano: Schnidler Bunge Pondal Rios; Bunge Urquiza Bazterrica; Bunge Urquiza Arias Herrexa Vegas: Aguirre Ibañez Stegmann; Aguirre Stegmann Ugark: Aguirre Ugarte; Santamarina Aguirre Ugarte; Huergo Aguirre Ugarte; Aguirre Ituarte Anchorena Ibañez; Aguirre Anchorena Lynch; Aguirt: Lynch: Agote Aguirre Lynch: Ibargh ren Uriburt Aguirre Lynch: Ibargliren Agijric Schindler Rosa: Ibarguren Aguirre Udaondo Soto; Aubone Quiroga Ibarguren Aguirre; Ibarguren Aguirre Verstraeten An chorena: Ibarguren Aguirre Muría Obejero; Van Peborgh Ibarguren Aguirre: Gallardo Pirovano Ibarguren Schindler: Ibarguren Schindlè Estrada Achaval; Beccar Varela Ibarguren Schindler: Ibarguren Schindler Lopez Saubidet: Ibarguren Schindler Cané Bustillo; Bosch Seeber Ibaryuren Udaondo: Moreno Vivot Ibarguren Udaondo; Aubone Ibarguren Loper. Saubidet; Uribelarra Pirovano Aubone Ibarguren. Ibarguren Vers-
\end{abstract}

Fuente: Instituto Argentino de Ciencias Genealógicas, Revista, n. ${ }^{\circ}$ 17, Buenos Aires, 1997, pp. 117-120.

${ }^{53}$ MARTÍNEZ VIVOT, José María: El Tesoro de Valdez. Amores, odios y corrupción en el Buenos Aires del 1600, Buenos Aires, Gorguera Ediciones, 2003. Recoge algunos aspectos de este canario de forma novelada. 


\section{Bibliografia}

BIROCCO, Carlos: La élite de poder en Buenos Aires colonial: Cabildo y cabildantes entre los Habsburgos y los Borbones (1690-1726). Tesis de posgrado, Universidad Nacional de La Plata, Facultad de Humanidades y Ciencias de la Educación, 2015. Memoria Académica

\section{[<http: / / www.memoria.fahce.unlp.edu.ar/tesis/te.1167/te.1167.pdf>]}

CIORANESCU, Alejandro: Diccionario Biográfico de canarios-americanos, Santa Cruz de Tenerife, 1992, 2 Volúmenes.

COMELLA GUTIÉRREZ, Beatriz: "Los nombramientos episcopales para la Corona de Castilla bajo Felipe III, según el Archivo Histórico Nacional: una aproximación", en Hispania Sacra, n. ${ }^{\circ}$ LC, p. 122, julio-diciembre 2008, pp. 703-733. [<http://62.204.194.45/fez/eserv/bibliuned:DptoHEECFEDU-Articulos-Bcomella-7045/Comella_Beatriz_Nombramientos.pdf.>].

CUTOLO, Vicente Osvaldo: "Abogados criollos en el Buenos Aires del 1600". Cfr.:

$[<$ https: / / bibliotecavir-

tual.unl.edu.ar:8443/bitstream/handle/11185/3571/RU023_09_A007.p $\mathrm{df}>$ ].

FERNÁNDEZ DE BURZACO, Hugo: Aportes Biogenealógicos para un Padrón de Habitantes del Rio de la Plata, Buenos Aires, 1986-1991, 6 vols.

HENANDARIAS DE SAAVEDRA, Buenos Aires, Colección Felix Luna, Editorial Planeta, 2000.

IBARGUREN, Carlos (h.): "González Filiano", Instituto Argentino de Ciencias Genealógicas, Revista del Instituto Argentino de Ciencias Genealógicas, n. ${ }^{\circ}$ 17, Buenos Aires, 1997.

MARTÍnEZ VIVOT, José Maria: El Tesoro de Valdez. Amores, odios y corrupción en el Buenos Aires del 1600, Buenos Aires, Gorguera Ediciones, 2003.

MOLINA, Raúl A.: "Juan de Vergara, señor de vida y haciendas en el Buenos Aires del siglo XVII", Boletín de la Academia Nacional de la Historia, n. ${ }^{\circ}$ XXIV, Buenos Aires, 1950.

MOLINA, Raúl A.: "El primer banquero de Buenos Aires. Jerarquía alcanzada por su descendencia", Revista de Historia Argentina y Americana, n. ${ }^{\circ}$ II, Buenos Aires, 1961.

MOLINA, Raúl A.: Diccionario Biográfico de Buenos Aires 1580-1720, Buenos Aires, Academia Nacional de la Historia, 2000.

MOLINA, Raúl A.: Matrimonios, Bautismos y Defunciones de la Catedral de Buenos Aires, 1601-1644. Y legajos I y II de Expedientes Matrimoniales del Archivo del Arzobispado de Buenos Aires (Ex Curia Eclesiástica), Buenos Aires, Academia Americana de Genealogia, 2002.

CORTABARRÍA, Jorge Juan: "Raúl A. Molina y la historia de la Virgen de Luján", en Temas de historia argentina y americana, n. ${ }^{\circ}$ 6, Buenos Aires, Pontificia Universidad Católica Argentina, Facultad de Filosofia y Letras, enero-junio de 2005. 
MONTES-BRADLEY II, Saúl M.: Hidalgos, Marinos y Conquistadores. Los Montes del Caballito, sus ancestros y descendencia, South Boston, Virginia, 2014.

MOUTOKIAS, Zacarias: "Burocracia, contrabando y autotransformación de las élites: Buenos Aires en el siglo XVII". Anuario I. E. H. S., n. ${ }^{\circ}$ 3, Tandil, Argentina, 1988.

- "Contrabando y sector externo en Hispanoamérica colonial», en CARMAGNANI, Marcelo, Alicia HERNÁNDEZ CHÁVEZ, y Romano RUGGIERO (coords.): Para una historia de América II, México, Fondo de Cultura Económica, 1999, pp. 172-197.

PERUSSET VERAS, Macarena: "Elite y comercio en el temprano siglo XVII rioplatense", en Fronteras de la Historia, n. ${ }^{\circ}$ 10, ICANH, 2005.

- Contrabando y sociedad en el Río de la Plata colonial, Buenos Aires, Editorial Dunken, 2006.

- "Conductas y procedimientos fuera de la ley: comercio ilícito, líderes y prácticas", en Universitas Humanística, n. ${ }^{\circ}$ 63, enero-junio de 2007, Bogotá, Colombia, pp. 203-239

[<http: / /www.scielo.org.co/pdf/unih/n63/n63a11.pdf.>].

REAL ACADEMIA DE HISTORIA. ESPAÑA: Diccionario Biográfico electrónico. Consultas varias en red [<hhtp://dbe.rah.es $>$ ].

TORRE REVELLO, José: "Los gobernadores de Buenos Aires (1617-1777)", en LEVENE, Carlos (dir.): Historia de la Nación Argentina (desde los orígenes hasta la organización definitiva en 1862), Buenos Aires, Editorial Ateneo, 1939, vol. III.

VILlaloBOS R., Sergio: Comercio y contrabando en el Río de la Plata y Chile, 1700-1811, Buenos Aires, Editorial Universitaria de Buenos Aires, 1965. 